\title{
Anatomy of the ventricular septal defect in outflow tract defects: Similarities and differences
}

\author{
Meriem Mostefa-Kara, MD, ${ }^{\mathrm{a}, \mathrm{d}}$ Damien Bonnet, MD, PhD, ${ }^{\mathrm{a}, \mathrm{b}, \mathrm{c}}$ Emre Belli, MD, ${ }^{\mathrm{d}}$ Elie Fadel, MD, PhD, ${ }^{\mathrm{e}}$ and \\ Lucile Houyel, $\mathrm{MD}^{\mathrm{d}}$
}

\begin{abstract}
Objective: The study objective was to analyze the anatomy of the ventricular septal defect found in various phenotypes of outflow tract defects.

Methods: We reviewed 277 heart specimens with isolated outlet ventricular septal defect without subpulmonary stenosis (isolated outlet ventricular septal defect, 19); tetralogy of Fallot (71); tetralogy of Fallot with pulmonary atresia (51); common arterial trunk (54); double outlet right ventricle (65) with subaortic, doubly committed, or subpulmonary ventricular septal defect; and interrupted aortic arch type B (17). Special attention was paid to the rims of the ventricular septal defect viewed from the right ventricular side and the relationships between the tricuspid and aortic valves.
\end{abstract}

Results: The ventricular septal defect was always located in the outlet of the right ventricle, between the 2 limbs of the septal band. There was a fibrous continuity between the tricuspid and aortic valves in $74 \%$ of specimens with isolated outlet ventricular septal defect, $66 \%$ of specimens with tetralogy of Fallot, $39 \%$ of specimens with tetralogy of Fallot with pulmonary atresia, $4.6 \%$ of specimens with double outlet right ventricle, $1.8 \%$ of specimens with common arterial trunk, and zero of specimens with interrupted aortic arch type B $(P<.005)$. When present, this continuity always involved the anterior tricuspid leaflet.

Conclusions: The ventricular septal defect in outflow tract defects is always an outlet ventricular septal defect, cradled between the 2 limbs of the septal band. However, there are some differences regarding the posteroinferior and superior rims of the ventricular septal defect. These differences suggest an anatomic continuum from the isolated outlet ventricular septal defect to the interrupted aortic arch type B rather than distinct physiologic phenotypes, related to various degrees of abnormal rotation of the outflow tract during heart development: minimal in isolated outlet ventricular septal defect; incomplete in tetralogy of Fallot, tetralogy of Fallot with pulmonary atresia, and double outlet right ventricle; absent in common arterial trunk; and excessive in interrupted aortic arch type B. (J Thorac Cardiovasc Surg 2015;149:682-8)

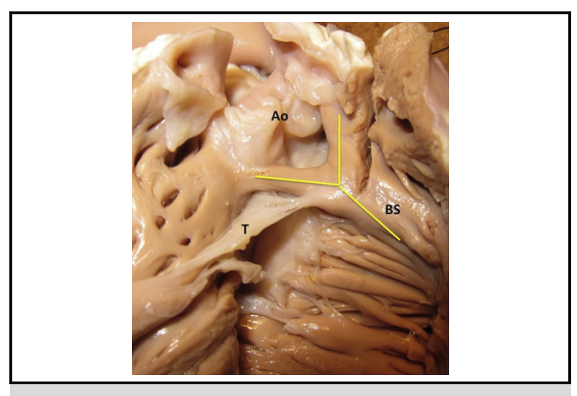

An outlet VSD viewed from the right ventricle, located between the 2 limbs of the septal band.

\section{Central Message}

The VSD in outflow tract defects is always an outlet VSD, cradled between the 2 limbs of the septal band. Differences between these defects regarding the presence of aortotricuspid continuity suggest an anatomic continuum, related to various degrees of abnormal rotation of the outflow tract during the heart development.

\section{Author Perspective}

This anatomic study offers a new perspective on the group of outflow tract defects. The cornerstone of these defects is the outlet VSD, which always opens in the outflow tract of the right ventricle between the 2 limbs of the septal band, irrespective of the presence or absence of a fibrous continuity between the aortic and the tricuspid valves. This anatomic approach underlines the anatomic difference between outlet VSD and isolated central perimembranous VSD. By reinforcing the hypothesis of an embryologic origin common to all outflow tract defects, it might help us to clarify the classification and terminology of VSD.
Outflow tract defects including cardiac neural crest defects (so-called conotruncal defects) and transposition of the great arteries (TGA) are due to an abnormal formation of

From the Université Paris Descartes, ${ }^{\text {a }}$ Sorbonne Paris Cité, Paris, Imagine Institute Hôpital Necker enfants Malades, Paris, France; Paediatric Cardiology, ${ }^{\text {b }}$ Centre de Référence Malformations Cardiaques Congénitales Complexes - M3C, Necker Hospital for Sick Children, Assistance Publique des Hopitaux de Paris, Paris, France; Université Paris Descartes, ${ }^{c}$ Sorbonne Paris Cité, Paris, France; Congenital Cardiac Surgery, ${ }^{\mathrm{d}}$ Hôpital Marie-Lannelongue, CMR-M3C, Université Paris-Sud, Le Plessis-Robinson, France; and Laboratory of Surgical Research, ${ }^{\mathrm{e}}$ Hôpital Marie-Lannelongue, Le Plessis-Robinson, France. the outflow tract during cardiac development. ${ }^{1}$ Cardiac neural crest defects are due to a defect of migration of cardiac neural crest cells, leading to a lack of elongation of the outflow tract and eventually to an abnormal development of the outlet part of the ventricular septum. ${ }^{2}$ This common embryologic origin expresses itself within different anatomic phenotypes, including common arterial

Funded by a grant from the French Society of Cardiology.

Received for publication May 27, 2014; revisions received Nov 17, 2014; accepted for publication Nov 29, 2014; available ahead of print Feb 20, 2015.

Address for reprints: Meriem Mostefa-Kara, MD, 149 rue de Sèvres, 75015 Paris, France (E-mail: meriem.kara@gmail.com).

$0022-5223 / \$ 36.00$

Copyright () 2015 by The American Association for Thoracic Surgery

http://dx.doi.org/10.1016/j.jtcvs.2014.11.087 


$$
\begin{aligned}
& \text { Abbreviations and Acronyms } \\
& \begin{aligned}
\text { CAT } & =\text { common arterial trunk } \\
\text { DORV } & =\text { double outlet right ventricle } \\
\text { IAA } & =\text { interrupted aortic arch } \\
\text { PA } & =\text { pulmonary atresia } \\
\text { TGA } & =\text { transposition of the great arteries } \\
\text { TOF } & =\text { tetralogy of Fallot } \\
\text { VSD } & =\text { ventricular septal defect }
\end{aligned}
\end{aligned}
$$

trunk (CAT); tetralogy of Fallot (TOF) with or without pulmonary atresia (PA) or absent pulmonary valve; double outlet right ventricle (DORV) with subaortic, doubly committed, or subpulmonary ventricular septal defect (VSD); some forms of interruption of the aortic arch; and isolated VSD opening in the outlet of the right ventricle, with outlet septal malalignment. ${ }^{3}$ From a purely anatomic standpoint, these congenital heart defects are described as different, but all share the presence of a VSD, as described by several authors. ${ }^{4-8}$ Embryologically, this VSD is secondary to a lack of fusion between the outlet septum and the septal band or septomarginal trabeculation because of an incomplete rotation of the outflow tract. ${ }^{3,9}$ The aim of this study was to analyze the anatomy of the VSD found in the various phenotypes of outflow tract defects on heart specimens and to determine its localization, its anatomic characteristics, and the rims and relationships to adjacent structures to search for similarities or differences among these various phenotypes.

\section{MATERIAL AND METHODS}

We analyzed the anatomy of the VSD in human hearts with outflow tract defects using the heart specimens of the anatomic collection of the French Reference Center for Complex Congenital Heart Defects (M3C) in the Marie-Lannelongue Hospital. This collection includes 1366 heart specimens fixed in $10 \%$ formalin. We studied 277 heart specimens with outflow tract defects, including 19 isolated VSDs opening into the outlet of the right ventricle with overriding aorta but no subpulmonary stenosis (isolated outlet VSD, including malalignment and doubly committed phenotypes); 71 with TOF ( 8 of them with absent pulmonary valve); 51 with TOF-PA; 54 with CAT; 65 with DORV (including 36 with subaortic VSD, 4 with doubly committed VSD, and 25 with subpulmonary VSD); and 17 with interrupted aortic arch (IAA) type B.

We chose to exclude hearts with DORV with noncommitted VSD, because these defects are supposed to be related with distinct embryologic mechanisms. ${ }^{10}$ We also excluded IAA type A because this defect is generally thought to be an extreme form of aortic coarctation. ${ }^{11}$ There was no IAA type $\mathrm{C}$ in the collection. Although TGA is also an outflow tract defect, we chose to study 104 hearts with TGA and associated VSD separately because several epidemiologic, experimental, and genetic studies tend to demonstrate that the morphogenesis of TGA could involve in part the laterality genes, such as ZIC3,CFC1, and NODAL, ${ }^{12-14}$ leading to a possible disturbance of the "rotational" aspect of wedging ${ }^{15}$ and to the fusion of the outflow tract cushions in a parallel and not spiraling fashion. ${ }^{16}$ In addition, we analyzed 15 hearts with dilated or restrictive cardiomyopathy without any associated congenital heart defects as controls.

The intracardiac anatomy of each heart specimen was studied with particular attention paid to the VSD. The exact localization of the VSD and its borders were carefully described viewed from the right ventricular side, as well as the relationship between the tricuspid and aortic valves, looking for a fibrous continuity between these 2 valves, and particularly which tricuspid leaflet was involved in this continuity.

We chose to define the curved surface of the VSD by the surface that will be closed by the surgeon. ${ }^{9}$ This surface is different depending on whether each arterial trunk arises from its own ventricle or both arterial trunks arise from the same ventricle as in DORV. In DORV, the VSD, roofed by the outlet septum or its fibrous remnant, is different from the interventricular communication that lies in the plane of the ventricular septum and is roofed by the inner curvature of the heart.

The morphologically normal hearts were used as controls to analyze precisely the anatomy of the membranous septum and its relations with the limbs of the septal band or septomarginal trabeculation. We also looked for the presence or absence of a demonstrable outlet septum and its orientation when the outlet septum was deviated anteriorly (into the right ventricle) or posteriorly (into the left ventricle) relative to the axis of the remainder muscular ventricular septum.

\section{Normal Anatomy of the Right Ventricle}

To fully describe the morphologic features of the VSD, we have to clearly define the terminology used to characterize the different parts of the right ventricle (Figure 1).

The ventriculo-infundibular fold (grouping together parietal band and subpulmonary conus) is a muscular band that separates the anterior leaflet of the tricuspid valve from the leaflets of the pulmonary valve in the normal heart. ${ }^{17-19}$ The left extremity of the ventriculo-infundibular fold represents the upper part of the ventricular septum: the outlet (or conal) septum, which is fused with the upper extremity of the septal band (or septomarginal trabeculation), between its 2 limbs, anterosuperior and posteroinferior. In the normal heart, the posteroinferior limb of the septal band, which carries the papillary muscle of the conus and its attachments, is not fused with the ventriculo-infundibular fold but is separated from it by the atrioventricular part of the membranous septum, connecting the anterior leaflet of the tricuspid valve with the leaflets of the aortic valve. ${ }^{20}$ The interventricular part of the membranous septum connects the septal leaflet of the tricuspid valve with the right coronary and the noncoronary leaflets of the aortic valve (Figure 2). This will help us to analyze the localization of the VSD in the specimens and to describe precisely the rims of the VSD.

\section{Statistical Analysis}

StatView software (SAS Institute Inc, Cary, NC) was used for data analysis. The qualitative anatomic variables were presented with percentages. A chi-square test analysis was used to evaluate the possible differences between the parameters.

\section{RESULTS \\ Localization of the Ventricular Septal Defect}

All heart specimens, except 1 with an IAA type B, had a VSD. This VSD was, as expected, always located in the outlet of the right ventricle, between the 2 limbs of the septal band (outlet-type VSD) (Figure 3). However, we could distinguish some anatomic differences within these outlet VSDs, depending on the rims of the VSD and more precisely on the presence or absence of a fibrous continuity between the leaflets of the aortic (or truncal) and tricuspid valves, and on the presence or absence of an outlet septum. 


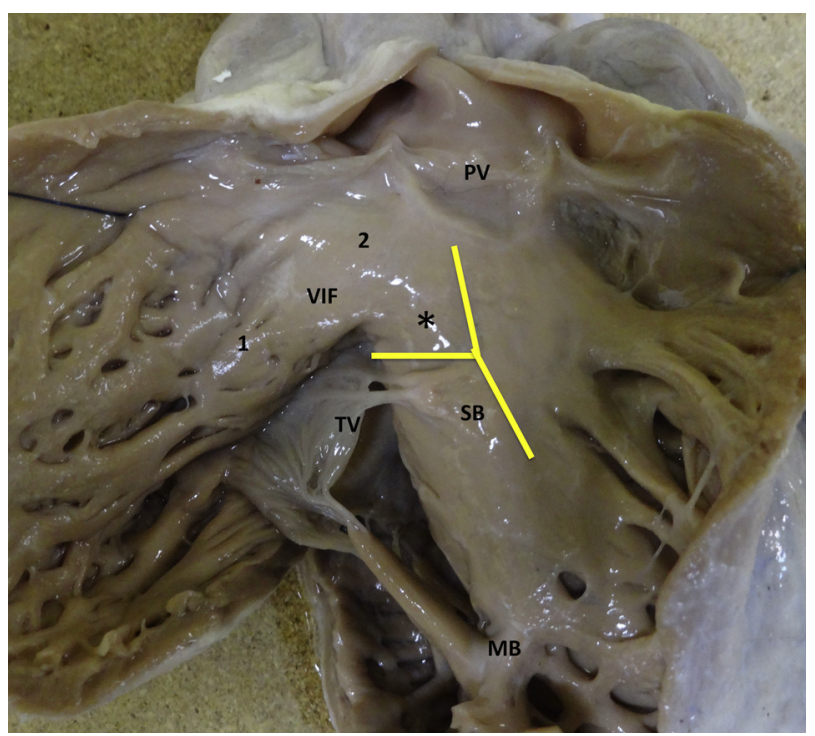

FIGURE 1. Right ventricular aspect of the ventricular septum in a normal heart. The muscular bands of the right ventricle are the ventriculo-infundibular fold, including the parietal band (1) and subpulmonary conus (2); the outlet septum $(*)$; the septal band or septomarginal trabeculation with its 2 limbs, anterosuperior and posteroinferior (yellow $Y$ ); the moderator band; and the anterior papillary muscle of the tricuspid valve. $M B$, Moderator band; $P V$, pulmonary valve; $T V$, tricuspid valve; $V I F$, ventriculo-infundibular fold; $S B$, septal band.

\section{Rims of the Ventricular Septal Defect}

This anatomic characteristic could be analyzed in all specimens except 2 with TOF-PA, because previous surgery made the analysis of the rims of the VSD difficult. All VSDs were located in the outlet of the right ventricle, between the 2 limbs of the septal band, but there were differences between them regarding the nature of their rims and more particularly of the posteroinferior rim. We identified 2 different types: one with a fibrous continuity between the aortic (or truncal) valve and the tricuspid valve in the posteroinferior quadrant of the VSD, and one with an entirely posteroinferior muscular rim (Figure 4).

Fibrous continuity was found in 14 of 19 isolated outlet VSDs (74\%), 47 of 71 specimens with TOF (66\%), 19 of 49 specimens with TOF-PA $(39 \%), 3$ of 65 specimens with DORV $(4.6 \%), 1$ of 54 specimens with CAT $(1.8 \%)$, and zero of the 16 specimens IAA with a VSD $(P<.0001)$ (Figure 5). In all these specimens, the fibrous continuity between the aortic (or truncal) and tricuspid valves represented the posteroinferior border of the VSD: The posteroinferior limb of the septal band was not fused with the ventriculo-infundibular fold. This fibrous continuity always involved the anterior leaflet, and not the septal leaflet, of the tricuspid valve (Figure 4).

In all of the morphologically normal hearts studied as controls, the posteroinferior limb of the septal band was always separated from the ventriculo-infundibular fold by

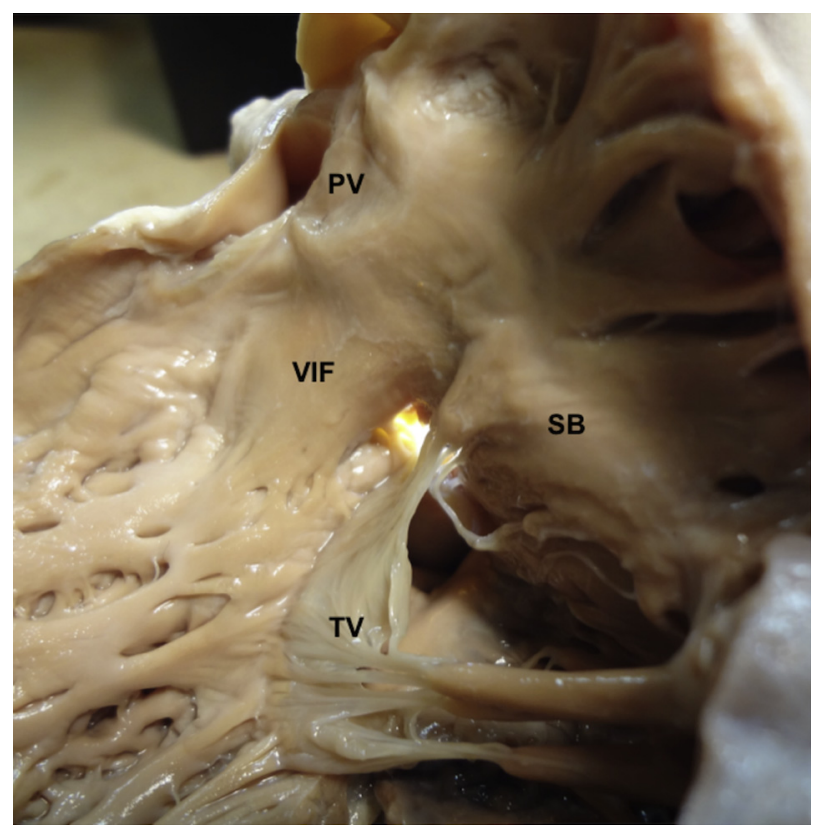

FIGURE 2. Localization of the membranous septum in the normal heart viewed from the right ventricle. The membranous septum (transilluminated) ensures a fibrous continuity between the anteroseptal commissure of the tricuspid valve and the aortic valve. The posteroinferior limb of the septal band is separated from the ventriculo-infundibular fold by the membranous septum. $P V$, Pulmonary valve; $S B$, septal band; $T V$, tricuspid valve; VIF, ventriculo-infundibular fold.

the atrioventricular part of the membranous septum, connecting the anterior leaflet of the tricuspid valve and the aortic leaflets (Figure 2).

In the hearts without fibrous continuity between the aortic (or truncal) and tricuspid valves, the posteroinferior rim of the VSD was entirely muscular because of the fusion of the posteroinferior limb of the septal band with the ventriculo-infundibular fold (Figure 4).

For heart specimens with DORV, a fibrous continuity was found in 2 of 36 with DORV and subaortic VSD, 1 of 4 with DORV and doubly committed VSD, and zero with DORV and subpulmonary VSD.

\section{Presence of an Outlet Septum}

The outlet septum could be analyzed in all hearts except 2 with TOF-PA because of previous surgery. A muscular outlet septum could be demonstrated in 16 of 19 with outlet VSD $(84 \%), 68$ of 71 with TOF $(96 \%), 20$ of 49 with TOF-PA $(40 \%)$, 61 of 65 with DORV $(94 \%)$, zero with CAT, and 13 of 16 with IAA $(81 \%)(P<.0001)$.

In TOF and TOF-PA, the outlet septum, when present, was always malaligned with the rest of the septum and deviated anteriorly. The inability to identify an outlet septum in $60 \%$ of TOF-PA was probably due to its excessive anterior deviation, making it indistinguishable from the anterior wall of the right ventricle. The outlet 

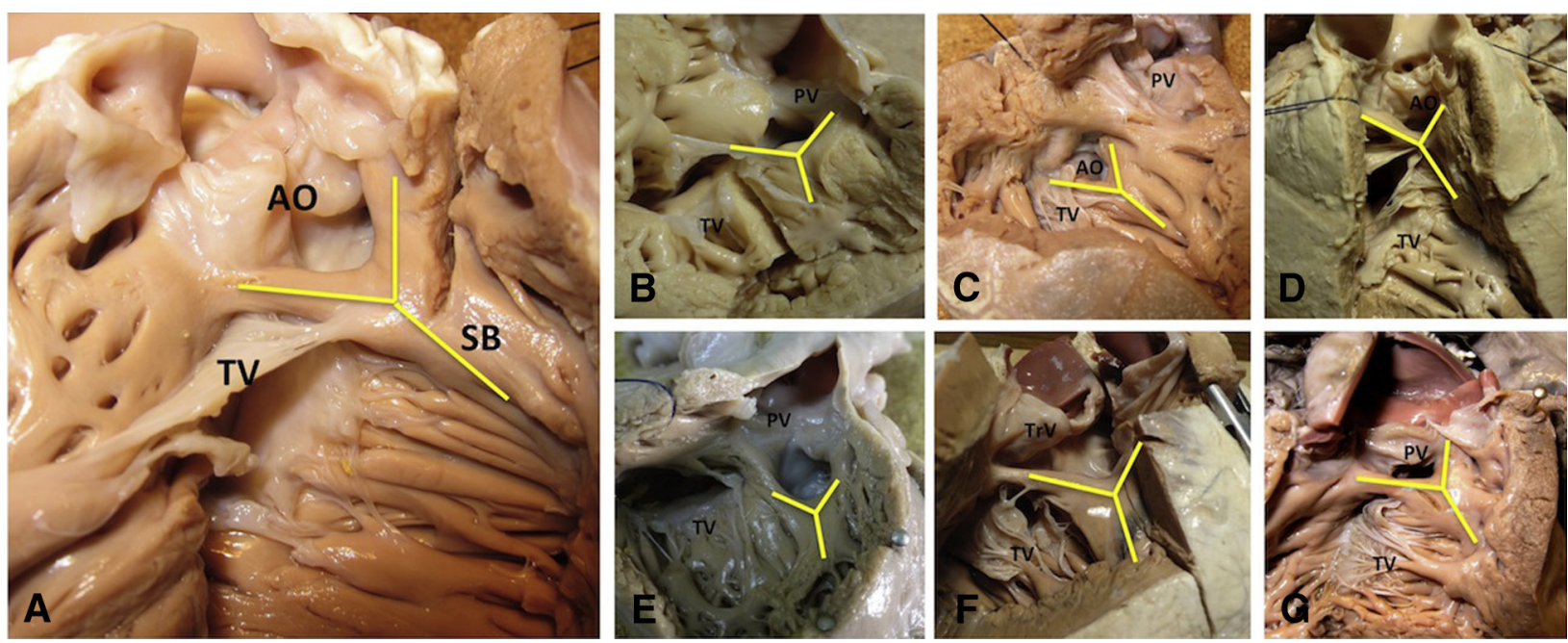

FIGURE 3. Localization of the VSD in heart specimens with various outflow tract defects: TOF-PA (A), isolated outlet VSD (B), TOF (C), DORV with subaortic VSD (D), DORV with subpulmonary VSD (E), CAT (F), and IAA type B viewed from the right ventricle (G). The localization of the VSD is always the same, in the outlet of the right ventricle, between the 2 limbs of the septal band (anterosuperior and posteroinferior) (yellow $Y$ ). AO, Aorta; $S B$, septal band; $P V$, pulmonary valve; $\operatorname{Tr} V$, truncal valve; $T V$, tricuspid valve.

septum was fibrous and not muscular in 2 hearts with TOF, and this fibrous remnant created valvar pulmonary obstruction by restricting the diameter of the pulmonary annulus. One heart with TOF and absent pulmonary valve had total absence of outlet septum with contiguous pulmonary and aortic valve without any fibrous remnant.

In DORV with doubly committed VSD, the outlet septum was always fibrous (fibrous raphe between the aortic and the pulmonary valve) and not muscular. In DORV with subaortic VSD, the outlet septum was always muscular and malaligned with the rest of the ventricular septum.
It was deviated anteriorly, creating subpulmonary obstruction, in 31 of 36 specimens (Fallot-type DORV). In DORV with subpulmonary VSD, the outlet septum was always muscular and was deviated posteriorly, creating subaortic obstruction, in 10 of 25 specimens.

In IAA type B, 3 hearts had a doubly committed VSD with fibrous outlet septum and subaortic obstruction. Whether muscular or fibrous, the outlet septum was always malaligned with the rest of the ventricular septum and deviated posteriorly, creating a subaortic obstruction (Figure E1).
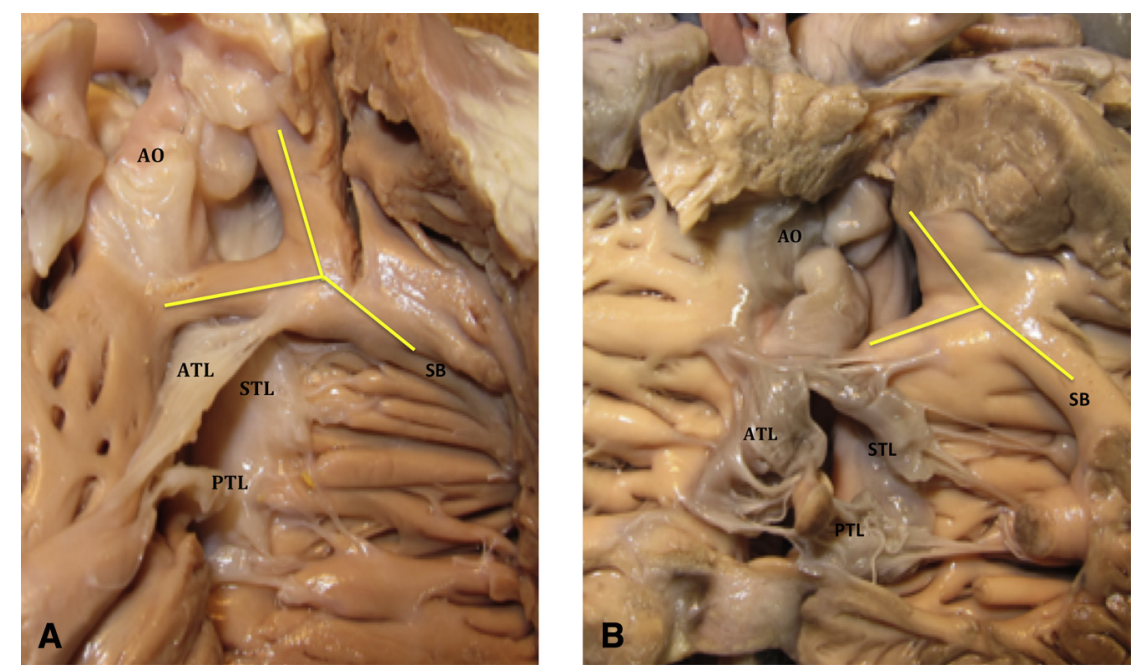

FIGURE 4. Two heart specimens with TOF-PA. A, The outlet VSD, located between the 2 limbs of the septal band (yellow Y), has entirely muscular rims. $\mathrm{B}$, Outlet VSD (yellow $Y$ ) with fibrous continuity between the aortic and tricuspid valves. This continuity involves almost exclusively the anterior leaflet of the tricuspid valve, disrupting the muscular continuity between the ventriculo-infundibular fold and the posteroinferior limb of the septal band. $A O$, Aorta; $A T L$, anterior tricuspid leaflet; $P T L$, posterior tricuspid leaflet; $S B$, septal band; $S T L$, septal tricuspid leaflet. 


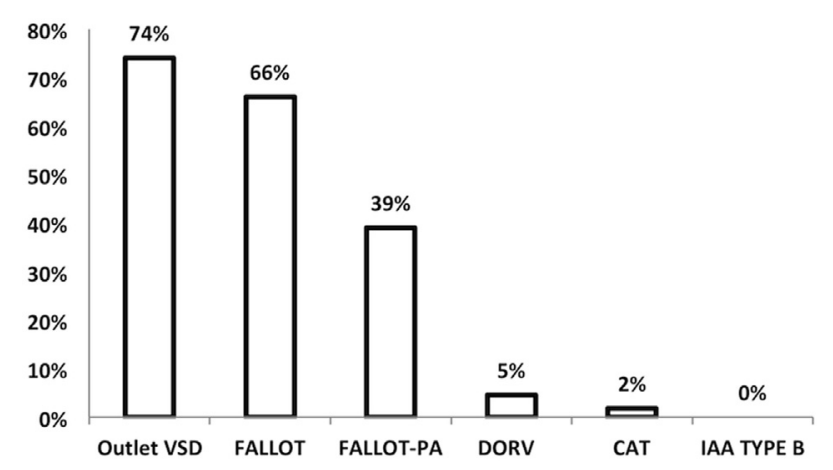

FIGURE 5. The rate of fibrous continuity between the aortic and tricuspid valves in the heart specimens with outflow tract defects. The highest rate was found in the group with isolated outlet VSD, then in TOF and TOF-PA, rarely in DORV and CAT, and absent in IAA type B. $C A T$, Common arterial trunk; DORV, double outlet right ventricle; $I A A$, interruption of the aortic arch; $P A$, pulmonary atresia; $V S D$, ventricular septal defect.

\section{DISCUSSION}

The VSD in outflow tract defects always opens in the outlet of the right ventricle, between the 2 limbs of the septal band. The defects observed experimentally after ablation of the cardiac neural crest include complete absence of septation of the outflow tract (CAT) and malalignment defects (DORV with subaortic, doubly committed, or subpulmonary VSD; TOF and variants; overriding aorta; and IAA type B). ${ }^{3}$

CAT is defined by a single vessel originating from the heart, with a common arterial valve, producing the coronary arteries, at least 1 pulmonary artery, and systemic arteries. ${ }^{4}$ Although rare cases with intact septum have been described, ${ }^{21}$ CAT almost always includes an outlet VSD located between the 2 limbs of the septal band. ${ }^{22}$ There is no outlet septum; the superior rim of the VSD is formed by the common arterial valve.

Malalignment defects are due to a lack of elongation of the outflow tract during the different phases of cardiac looping, ${ }^{3}$ preventing normal wedging of the aortic valve between the tricuspid and mitral valves, with an outflow tract that is shorter and straighter than normal. ${ }^{2}$ This phenotype is due to a lack of addition of myocardial cells to the developing outflow tract by the secondary heart field. ${ }^{23,24}$ All malalignment defects include a VSD due to the malalignment and the absence of fusion between the outlet septum and the rest of the ventricular septum, the outlet septum then being an exclusively right ventricular structure. ${ }^{2,9}$ All authors agree that this VSD is cradled between the 2 limbs of the septal band. ${ }^{17-19,22,25-27}$ Indeed, we found such an outlet VSD in all the heart specimens studied. The only exception was seen in 1 heart with IAA type B that had no VSD. Such cases, although rare, have been described in the literature. $^{28}$
Although this type of VSD was common to all outflow tract defects examined, we have found that its anatomic variants are distributed differently according to the defect involved, especially when focusing on the posteroinferior rim and particularly on the aortic-tricuspid fibrous continuity. We show that this continuity occurs with different frequency among the various outflow tract defects studied: The highest rate was found in isolated outlet VSD, then decreasing progressively from TOF to TOF-PA, then DORV, and to become exceedingly rare in CAT and absent in IAA type B. These differences suggest an anatomic continuum from isolated outlet VSD to IAA type $\mathrm{B}$, rather than distinct physiologic phenotypes, related to various degrees of abnormal rotation of the outflow tract: minimal in isolated outlet VSD; incomplete in TOF, TOF-PA, and DORV; absent in CAT; and probably excessive in IAA type B. We recently demonstrated that the pattern of the coronary orifices in outflow tract defects varies in a similar way according to the degree of lack of rotation of the outflow tract during cardiac development. ${ }^{29}$ The anatomic variations in the posteroinferior rim of the VSD found in the group of cardiac defects in the current study confirm these findings.

The high rate of aortic-tricuspid continuity found in isolated outlet VSD is reminiscent of the anatomic characteristics of the normal heart. In the normal heart, the rotation of the outflow tract is complete, and the wedging of the aorta between the tricuspid and mitral valves allows not only for the mitro-aortic fibrous continuity but also for the tricuspid-aortic continuity through the atrioventricular part of the membranous septum. ${ }^{9}$ This fibrous continuity can be seen from the right ventricular side below the ventriculo-infundibular fold, involving the anterior leaflet of the tricuspid valve, and disrupting the muscular fusion between the ventriculo-infundibular fold and the posteroinferior limb of the septal band or septomarginal trabeculation. ${ }^{20}$

The development of the ventricular septum has been thoroughly analyzed in murine embryonic hearts at different stages of development, using high-resolution episcopic microscopy. ${ }^{9}$ The results of this study are in accordance with our anatomic findings. Ventricular septation is achieved when the rotation of the aortic root and its transfer toward the left ventricle are complete. The perfect alignment between the outlet septum and the muscular septum then permits the fusion between the outlet septum, formed by the outflow tract cushions, and the septal band between its 2 limbs. The atrioventricular endocardial cushion tissue and the left outflow tract cushion will ultimately close the remaining small communication between the 2 ventricles, forming the membranous part of the ventricular septum. ${ }^{9}$ In other words, it is the complete wedging of the aorta that permits the formation of the membranous septum. We can infer from this study that 
the rotation or wedging may be less achieved in the subgroup of outlet VSDs with entirely muscular borders than in outlet VSDs with tricuspid-to-aortic fibrous continuity. This is consistent with our results, the rate of VSD with entirely muscular borders increasing from isolated outlet VSD to CAT and IAA type B. This reinforces the hypothesis of an anatomic continuum according to the degree of rotation of the outflow tract.

\section{Ventricular Septal Defect in Transposition of the Great Arteries}

To complete this study, we analyzed separately 104 hearts with TGA and associated VSD. In this group, the VSD was from the outlet type, cradled between the 2 limbs of the septal band, in only $40 \%$ of the specimens (42/104). The posteroinferior rim of the VSD was always muscular, as in DORV with subpulmonary VSD. The outlet septum was muscular in 39 of these 42 specimens and fibrous in 3 specimens. Other VSDs were muscular in 26 specimens, "central" perimembranous in 27 specimens, and from the inlet type in 9 specimens. The fact that, contrary to other outflow tract defects, the VSD in TGA is not always from the outlet type underlines the probable role of the laterality genes in the morphogenesis of TGA. ${ }^{12-14}$

\section{Is the Ventricular Septal Defect in Outflow Tract Defects Perimembranous?}

Although the inferior rim of the VSD in TOF is unequivocally described by all authors as formed by the superior part of the septal band and its 2 limbs, it is also considered to be paramembranous ${ }^{17}$ or perimembranous ${ }^{18}$ because of the presence of a fibrous aorto-tricuspid continuity in the majority of the cases. Outlet VSDs were classified by the European school as 3 types: (1) perimembranous, with fibrous continuity between the leaflets of the aortic valve and those of an atrioventricular valve; (2) muscular, with entirely muscular borders; and (3) subarterial, with fibrous continuity between the leaflets of the aortic and pulmonary valves. ${ }^{30,31}$ To paraphrase these authors, one could say that these 3 types of outlet VSDs are related in comparable fashion to the limbs of the septal band. ${ }^{30}$ To clarify terms and to differentiate this type of VSD from the isolated, or "central," perimembranous VSD, ${ }^{20,32}$ we propose to rename the outlet VSD with fibrous continuity between the aortic and tricuspid valves as "outlet VSD with perimembranous extension." This would emphasize the prominent anatomic characteristic of this VSD, common to all types of outflow tract defects except for TGA, namely, its location between the 2 limbs of the septal band, because of the absence of formation of the outlet septum or its lack of proper alignment and fusion with the underlying septal band during cardiac development.
To help solve this semantic problem, we analyzed 26 hearts with isolated central perimembranous VSD present in our anatomic collection. All of these VSDs were located behind the septal leaflet of the tricuspid valve, under the posteroinferior limb of the septal band, and not between the 2 limbs of the septal band. The outlet septum was intact and completely fused with the septal band. In addition, we observed that the fibrous continuity between the leaflets of the tricuspid and the aortic valve was different in outlet VSDs and in isolated "central" perimembranous VSDs: In the former, the anterior leaflet of the tricuspid valve was concerned, whereas in the latter, the fibrous continuity involved almost exclusively the septal leaflet of the tricuspid valve. This morphologic observation confirms the blatant anatomic difference between these 2 types of the VSDs and underlines the risk of confusion created by using the term "perimembranous" as the first determinant of the VSD. However, the presence of a fibrous continuity at the posteroinferior rim of the VSD is important for the surgeon because it makes the conduction axis vulnerable during surgery and therefore must be described specifically in the preoperative assessment of the defect.

\section{CONCLUSIONS}

This anatomic approach provides new perspectives on the group of outflow tract defects, especially the subgroup of cardiac neural crest defects. In all of the specimens studied, the VSD always opened in the outlet of the right ventricle, cradled between the 2 limbs of the septal band, irrespective of the presence or absence of a fibrous continuity between the aortic and tricuspid valves, and the presence of an outlet septum. Although the VSD is always the outlet type, there are some anatomic differences that seem to be related to the degree of rotation of the outflow tract during heart development. This anatomic approach places the outlet VSD as a cornerstone of the outflow tract defects, anatomically different from the isolated central perimembranous VSD. This may help us to better understand the anatomy of the VSDs and to clarify their classification and terminology.

\section{Conflict of Interest Statement}

Authors have nothing to disclose with regard to commercial support.

\section{References}

1. Bajolle F, Zaffran S, Kelly RG, Hadchouel J, Bonnet D, Brown NA, et al. Rotation of the myocardial wall of the outflow tract is implicated in the norma positioning of the great arteries. Circ Res. 2006;98:421-48.

2. Yelbuz TM, Waldo KL, Kumiski DH, Stadt HA, Wolfe RR, Leatherbury L, et al. Shortened outflow tract leads to altered cardiac looping after neural crest ablation. Circulation. 2002;106:504-10.

3. Hutson MR, Kirby ML. Model systems for the study of heart development and disease. Cardiac neural crest and conotruncal malformations. Semin Cell Dev Biol. 2007;18:101-10.

4. Jacobs ML. Congenital Heart Surgery Nomenclature and Database Project: truncus arteriosus. Ann Thorac Surg. 2000;69(4 suppl):S50-5. 
5. Jacobs ML. Congenital Heart Surgery Nomenclature and Database Project: tetralogy of Fallot. Ann Thorac Surg. 2000;69(4 suppl):S77-82.

6. Tchervenkov CI, Roy N. Congenital Heart Surgery Nomenclature and Database Project: pulmonary atresia-ventricular septal defect. Ann Thorac Surg. 2000;69(4 suppl):S97-105.

7. Walters HL III, Mavroudis C, Tchervenkov CI, Jacobs JP, Lacour-Gayet F, Jacobs ML. Congenital Heart Surgery Nomenclature and Database Project: double outlet right ventricle. Ann Thorac Surg. 2000;69(4 suppl):S249-63.

8. al-Marsafawy HM, Ho SY, Redington AN, Anderson RH. The relationship of the outlet septum to the aortic outflow tract in hearts with interruption of the aortic arch. J Thorac Cardiovasc Surg. 1995;109:1225-36.

9. Bailliard F, Spicer DE, Mohun TJ, Henry GW, Anderson RH. The problems that exist when considering the anatomic variability between the channels that permit interventricular shunting. Cardiol Young. 2015;25:15-28.

10. Van Praagh S, Davidoff A, Chin A, Shiel FS, Reynolds J, Van Praagh R. Double outlet right ventricle: anatomic types and developmental implications based on a study of 101 autopsied cases. Coeur. 1982;13:389-439.

11. Van Mierop LH, Kutsche LM. Interruption of the aortic arch and coarctation of the aorta: pathogenetic relations. Am J Cardiol. 1984;54:829-34.

12. Goldmuntz E, Bamford R, Karkera JD, de la Cruz J, Roessler E, Muenke M. CFC1 mutations in patients with transposition of the great arteries and double outlet right ventricle. Am J Hum Genet. 2002;70:776-80.

13. De Luca A, Sarkozy A, Consoli F, Ferese R, Guida V, Dentici ML, et al. Familial transposition of the great arteries caused by multiple mutations in laterality genes. Heart. 2010;96:673-7.

14. Unolt M, Putotto C, Silvestri LM, Marino D, Scarabotti A, Massaccesi V, et al. Transposition of the great arteries: new insights into the pathogenesis. Front Pediatr. 2013;1:11.

15. Digilio MC, Casey B, Toscano A, Calabro R, Pacileo G, Marasani M, et al. Complete transposition of the great arteries: patterns of congenital heart disease in familial precurrence. Circulation. 2001;104:2809-14.

16. Salih C, Brizard C, Penny DJ, Anderson RH. Transposition. In: Anderson RH, Baker EJ, Penny D, Redington AN, Rigby ML, Wernovsky G, eds. Pediatric Cardiology. 3rd ed. Philadelphia, PA: Churchill Livingstone; 2010: 795-818.

17. Van Praagh R. The first Stella van Praagh memorial lecture: the history and anatomy of tetralogy of Fallot. Semin Thorac Cardiovasc Surg Pediatr Card Surg Annu. 2009;12:19-38.

18. Anderson RH, Weinberg PM. The clinical anatomy of tetralogy of Fallot. Cardiol Young. 2005;15(Suppl 1):38.
19. Anderson RH, Jacobs ML. The anatomy of tetralogy of Fallot with pulmonary stenosis. Cardiol Young. 2008;18(suppl 3):12-21.

20. Soto B, Ceballos R, Kirklin JW. Ventricular septal defects: a surgical viewpoint. J Am Coll Cardiol. 1989;14:1291-7.

21. McElhinney DB, Reddy VM, Brook MM, Hanley FL. Repair of truncus arteriosus with intact ventricular septum (Van Praagh type B2) in a neonate. J Thorac Cardiovasc Surg. 1997;114:134-8.

22. Russell HM, Jacobs ML, Anderson RH, Mavroudis C, Spicer D, Corcrain E, et al A simplified categorization for common arterial trunk. J Thorac Cardiovasc Surg. 2011;141:645-53.

23. Waldo KL, Hutson MR, Ward CC, Zdanowicz M, Stadt HA, Kumiski D, et al. Secondary heart field contributes myocardium and smooth muscle to the arterial pole of the developing heart. Dev Biol. 2005;281:78-90.

24. Waldo KL, Hutson MR, Stadt HA, Zdanowicz M, Zdanowicz J, Kirby ML. Cardiac neural crest is necessary for normal addition of the myocardium to the arterial pole from the secondary heart field. Dev Biol. 2005;281:66-77.

25. Kreutzer J, Van Praagh R. Comparison of left ventricular outflow tract obstruction in interruption of the aortic arch and in coarctation of the aorta, with diagnostic, developmental, and surgical implications. Am J Cardiol. 2000; $86: 856-62$.

26. Celoria GC, Patton RB. Congenital absence of the aortic arch. Am Heart J. 1959; 58:407-13

27. Mahle WT, Martinez R, Silverman N, Cohen MS, Anderson RH. Anatomy, echocardiography, and surgical approach to double outlet right ventricle. Cardiol Young. 2008; 18(suppl 3):39-51.

28. Cazavet A, Seguela PE, Acar P, Leobon B. A new type of aortic arch interruption without significant patent ductus arteriosus and with no ventricular septal defect. J Thorac Cardiovasc Surg. 2012;143:237-9.

29. Houyel L, Bajolle F, Capderou A, Laux D, Parisot P, Bonnet D. The pattern of the coronary arterial orifices in hearts with congenital malformations of the outflow tracts: a marker of rotation of the outflow tract during cardiac development? J Anat. 2013;222:349-57.

30. Anderson RH, Spicer DE, Yo SJ, Jacobs JP, Aiello VD. Innovation and the role of cardiac morphologist. Cardiol Young. 2009;19(suppl 2):11-25.

31. Friedman BA, Hlavacek A, Chessa K, Shirali GS, Corcrain E, Spicer D, et al Clinico-morphological correlations in the categorization of holes between the ventricles. Ann Pediatr Cardiol. 2010;3:12-24.

32. Van Praagh R, Geva T, Kreutzer J. Ventricular septal defects: how shall we describe, name and classify them? J Am Coll Cardiol. 1989;14:1298-9. 


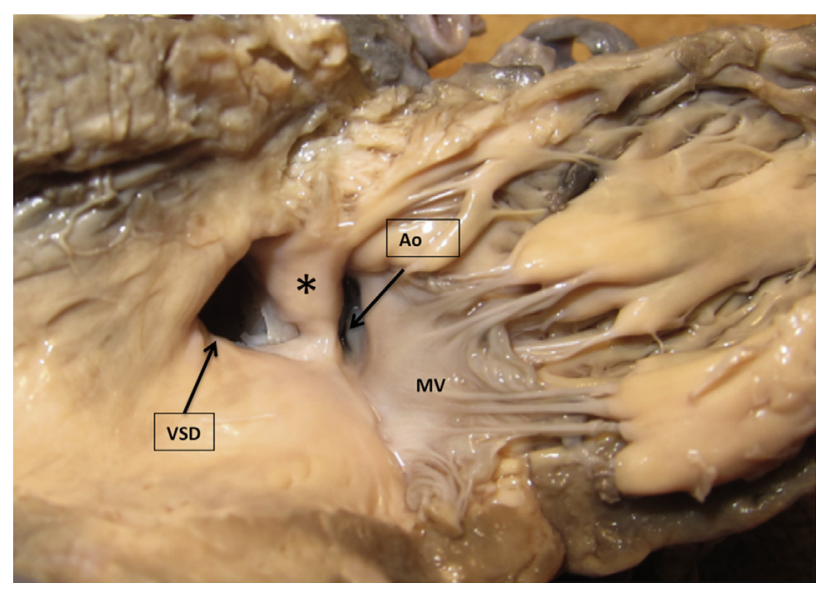

FIGURE E1. Heart specimen with IAA type B viewed from the left ventricle. The VSD is an outlet VSD. The outlet septum (*) is deviated posteriorly, creating a subaortic obstruction. Ao, Aorta; $M V$, mitral valve; $V S D$, ventricular septal defect. 